\title{
Photostabilization of Phenoxyacetic Acid Herbicides MCPA and Mecoprop by Hydroxypropyl- $\beta$-cyclodextrin
}

\author{
Cátia Costa, ${ }^{1}$ Sílvia Maia, ${ }^{1,2}$ Paulo Silva, ${ }^{1}$ Jorge Garrido, ${ }^{1,2}$ \\ Fernanda Borges, ${ }^{2}$ and E. Manuela Garrido ${ }^{1,2}$ \\ ${ }^{1}$ Departamento de Engenharia Química, Instituto Superior de Engenharia do Porto (ISEP), Instituto Politécnico do Porto, \\ Rua Dr. António Bernardino de Almeida 431, 4200-072 Porto, Portugal \\ ${ }^{2}$ CIQ/Departamento de Química e Bioquímica, Faculdade de Ciências, Universidade do Porto, 4169-007 Porto, Portugal
}

Correspondence should be addressed to Jorge Garrido; jjg@isep.ipp.pt and E. Manuela Garrido; emg@isep.ipp.pt

Received 31 May 2013; Accepted 6 August 2013

Academic Editor: Hongtao Yu

Copyright (C) 2013 Cátia Costa et al. This is an open access article distributed under the Creative Commons Attribution License, which permits unrestricted use, distribution, and reproduction in any medium, provided the original work is properly cited.

\begin{abstract}
New strategies to reduce the environmental and economic costs of pesticides use are currently under study. Microencapsulation has been used as a versatile tool for the production of controlled release agricultural formulations. In this study, the photochemical degradation of the herbicides MCPA and mecoprop has been investigated in different aqueous media such as ultrapure and river water under simulated solar irradiation. To explore the possibility of introducing cyclodextrins in the herbicide formulations, the photodegradation study of the inclusion complexes of MCPA and mecoprop with (2-hydroxypropyl)- $\beta$-cyclodextrin (HP- $\beta$-CD) was also performed. The half-lives of MCPA and mecoprop inclusion complexes were increased approximately by a factor of three related to the free molecules. Additionally, it has been shown that the photodegradation of MCPA and mecoprop is influenced by their structural features. The additional methyl group existing in mecoprop molecular structure has a positive influence on the stabilization of the radical intermediate formed in the first stage of photodegradation of both herbicides. The results found indicated that MCPA and mecoprop form inclusion complexes with HP- $\beta$-CD showing higher photostability compared to free herbicides indicating that $\mathrm{HP}-\beta$-CD may serve as ingredient in these herbicide formulations.
\end{abstract}

\section{Introduction}

Human population is constantly exposed to numerous chemical species present in the environment. Pesticides, a broad group of biologically active chemicals used for pest management, are among the most widely used chemicals in the world, and also among the most dangerous to human health. Among them, chlorophenoxy herbicides have received special attention because of their wide distribution and extensive use as plant growth regulators. Chlorophenoxy herbicides can be easily transferred to surface and ground waters due to their polar nature and relatively good solubility [13]. Furthermore, the toxicity of this type of herbicides is recognized, and the high-level exposure has been shown to be hepatotoxic as well as nephrotoxic in animal studies. They may cause, for instance, human chronic liver injury, nonHodgkin's lymphoma, soft tissue sarcoma, and malignant lymphoma [4-6].
As one of the most widely used herbicides in the world, 2,4-dichlorophenoxyacetic acid (2,4-D) continues to be one of the most studied pesticides, both in animals and in humans. Yet 4-chloro-2-methylphenoxyacetic acid (MCPA) and 2-(4-chloro-2-methylphenoxy)propanoic acid (mecoprop, MCPP) continue to be commercially important herbicides with widespread use, particularly in western Europe. In fact, MCPA and mecoprop (Scheme 1) are powerful, selective, and extensively used chlorophenoxy herbicides usually applied against broad-leaf weeds primarily in cereal and grass seed crops. In Portugal, MCPA still remain one of the most often used herbicides for rice crops [7]. Like the other phenoxy compounds, they are widespread in the environment and have been detected in agricultural drainage water, ground water, and sometimes even in water supplies intended for human use [8-11]. Former studies have shown that MCPA and mecoprop are photodegradable substances in groundwater and drinking water. Moreover, one MCPA 


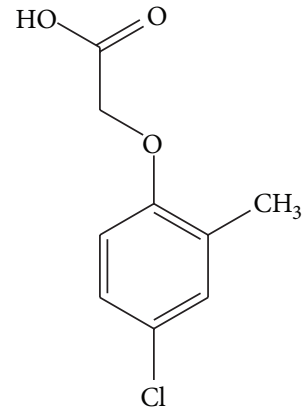

(a)<smiles>Cc1cc(Cl)ccc1OC(C)C(=O)O</smiles>

(b)<smiles>Cc1cc(Cl)ccc1O</smiles>

(c)

Scheme 1: Chemical structures of (a) MCPA, (b) mecoprop, and its main photodegradation product (c) 4-chloro-2-methylphenol.

photodegradation intermediate is listed, in the priority pollutants of the European Community and the US Environmental Protection Agency, as hazardous to human health [12, 13].

New strategies to reduce the environmental and economic costs of pesticides use are currently under study. Although sometimes the conventional formulations may be incorporated directly as solids, they are generally dispersed or diluted in water to be applied as a spray on the crops and/or soil [14]. This situation causes problems of toxicity and environmental contamination in agricultural areas where conventional formulations are applied, as a consequence of the high doses necessary to compensate for losses resulting from chemical and/or biological degradation, photodecomposition, volatilization, absorption by plants and adsorption to soil colloids, runoff, and lixiviation, among others $[15,16]$. Systems capable of releasing a herbicide to the desired site at a controlled rate offer the potential of overcoming some of these problems and of allowing more efficient utilization of existing herbicides. Effective controlled release formulations of herbicides should be allowed extended periods of activity, while minimizing adverse environmental effects related to movement of the herbicide from the application site. Microencapsulation has been used as a versatile tool for the production of controlled release agricultural formulations $[14,16]$. The versatility of this method leads to the possibility of encapsulating a wide range of pesticides.

Cyclodextrins (CDs) comprise a family of well-known cyclic oligosaccharides derived from starch with a hydrophilic outer surface and a lipophilic central cavity. Thus, an important property of the CDs is the ability to form noncovalent host-guest inclusion complexes with a wide variety of organic molecules of appropriate shape and size, either in the solid phase or in aqueous solution $[19,20]$. Molecular encapsulation of pesticides by CDs can enhance the efficacy and facilitate formulation of these agrochemicals in a variety of ways, for example, by increasing their flowability, wettability, dissolution rate, and chemical and thermal stability and reducing their volatility [21, 22].

This work aimed to study the photodegradation process of herbicides MCPA and mecoprop in order to evaluate their environmental impact. The influence of microencapsulation of MCPA and mecoprop by (2-hydroxypropyl)- $\beta$ cyclodextrin (HP- $\beta$-CD) on its rate of photodegradation was also assessed. The structural features governing the photodegradation of these herbicides were also evaluated. The appraisal of the physicochemical properties of these inclusion complexes will lead to new understanding of how to increase the efficiency and effectiveness of crop protection products containing MCPA or mecoprop phenoxy herbicides.

\section{Experimental}

2.1. Reagents and Water Samples. 4-Chloro-2-methylphenoxyacetic acid (MCPA), 2-(4-chloro-2-methylphenoxy)propanoic acid (mecoprop, MCPP), and (2-hydro-xypropyl)$\beta$-cyclodextrin (HP- $\beta$-CD) were supplied by Sigma-Aldrich Química (Sintra, Portugal). Analytical grade reagents purchased from Merck (Darmstadt, Germany) were used without additional purification. The water used was purified with a Millipore system (Milli-Q-50 $18 \mathrm{M} \Omega \mathrm{cm}$ ).

Environmental water used in the experiments was collected from Leça river basin located in northern Portugal. The water samples were obtained from the top meter in $2.5 \mathrm{~L}$ brown glass bottles. Immediately after arrival in the laboratory, the samples were filtered through $1 \mu \mathrm{m}$ of glass fibre filters and $0.45 \mu \mathrm{m}$ of cellulose acetate filters, sequentially, to remove suspended particles, and refrigerated at $4^{\circ} \mathrm{C}$ prior to use.

The $\mathrm{pH} 4$ supporting electrolyte was prepared by diluting $41.0 \mathrm{~mL}$ of $0.2 \mathrm{M}$ acetic acid and $9.0 \mathrm{~mL}$ of $0.2 \mathrm{M}$ sodium acetate to $100 \mathrm{~mL}$.

2.2. Apparatus. Voltammetric experiments were performed using an Autolab PGSTAT 12 potentiostat/galvanostat (Metrohm Autolab, The Netherlands) in a one-compartment glass electrochemical cell equipped with a three-electrode system consisting of a bare or modified glassy carbon working electrode (GCE, $d=2 \mathrm{~mm}$ ), a platinum wire counter electrode, and an $\mathrm{Ag} / \mathrm{AgCl}$ (saturated $\mathrm{KCl}$ ) reference electrode. All measurements were carried out at room temperature.

A Crison $\mathrm{pH}$-meter with glass electrode was used for $\mathrm{pH}$ measurements (Crison, Spain).

2.3. Phase Solubility Studies. Phase solubility studies were carried out according to the procedure previously 
reported [23]. Briefly, an excess amount of MCPA or mecoprop $(30 \mathrm{mg})$ was added to $7.5 \mathrm{~mL}$ of aqueous solutions containing different concentrations of HP$\beta$-CD $(0-35 \mathrm{mM})$. Then, the suspensions were shaken on an incubator shaker (Ika KS $4000 \mathrm{i}$ ) at $25 \pm 2^{\circ} \mathrm{C}$ for 2 days. After equilibrium was reached, suspensions were centrifuged and the supernatant was withdrawn and properly diluted. The concentrations of MCPA and mecoprop were determined spectrophotometrically (Shimadzu UV-Vis Spectrophotometer, UV-1700 PharmaSpec, Japan) at $228 \mathrm{~nm}$. The apparent stability constants, $K_{s}$, were calculated from phase solubility diagrams with the assumption of $1: 1$ stoichiometry, according to the following equation:

$$
K_{s}=\frac{\text { slope }}{S_{0}(1-\text { slope })},
$$

where $\mathrm{S}_{0}$ is the solubility of MCPA or mecoprop in the absence of HP- $\beta$-CD.

2.4. Irradiation Experiments. Photodegradation rates of MCPA and mecoprop were determined in natural water (Leça river) and in ultrapure water under simulated solar radiation. Photodegradation studies were carried out using a thermostatic chamber equipped with Ultra-Vitalux $300 \mathrm{~W}$ (Osram) UV-Vis lamps to simulate solar radiations (UVA radiated power $315-400 \mathrm{~nm} 13.6 \mathrm{~W}$ and UVB radiated power $280-$ $315 \mathrm{~nm} \mathrm{3.0} \mathrm{W).} \mathrm{Aqueous} \mathrm{solutions} \mathrm{of} \mathrm{MCPA} \mathrm{and} \mathrm{mecoprop}$ $(100 \mathrm{~mL}, 0.5 \mathrm{mM})$ were maintained at room temperature and exposed (in a capped pyrex flask) to UV-Vis irradiation for 130 hours at a fixed distance of $35 \mathrm{~cm}$. The same experiment was carried out in the presence of HP- $\beta$-CD. Studies were carried out on MCPA and mecoprop samples at HP- $\beta$ $\mathrm{CD}$ concentration of $35.0 \mathrm{mM}$. Control experiments in the dark (blank experiments) under the same conditions and initial concentrations of MCPA and mecoprop were carried out in parallel for comparison without the application of light. At selected time intervals, samples were collected and quantitatively analyzed, after proper dilution, by square wave voltammetry (SWV) for the amount of the compound of interest remaining in the solution after irradiation based on external calibration. All experiments were carried out in duplicate at $25 \pm 1^{\circ} \mathrm{C}$.

2.5. Analysis of MCPA and Mecoprop. Photodegradation kinetics was performed with an Autolab PGSTAT 12 potentiostat/galvanostat. Voltammetric experiments were carried out as described elsewhere [24]. Briefly, stock standard solutions of MCPA and mecoprop (10 mM) were prepared in ethanol. For calibration curves, standard solutions were prepared in the voltammetric cell by adding accurate volumes of the stock standard solution of MCPA or mecoprop to the selected acetate buffer $\mathrm{pH} 4$ supporting electrolyte in order to obtain concentrations between 10 and $70 \mu \mathrm{M}$. SQW voltammograms were recorded from 0.5 to $1.5 \mathrm{~V}$ at a scan rate of $50 \mathrm{mV} \mathrm{s}^{-1}$. The calibration curve for SQW analysis was constructed by plotting the peak current against the MCPA or mecoprop concentration.

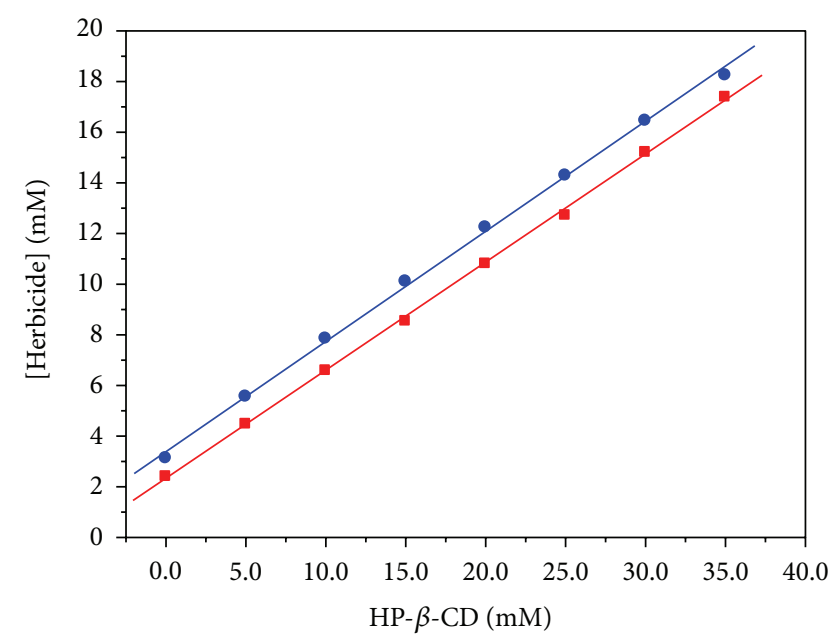

FIgURE 1: Phase solubility diagram obtained for herbicides (red square) MCPA and (blue circle) mecoprop and increasing concentrations of $\mathrm{HP}-\beta-\mathrm{CD}$ in water at $25^{\circ} \mathrm{C}$. Each point represents the mean of three determinations.

2.6. Analysis of Data. The disappearance rates of MCPA and mecoprop follow first-order kinetics given by

$$
C_{t}=C_{0} e^{-k t}
$$

where $C_{0}$ and $C_{t}$ are the concentrations at times 0 and $t, t$ is the irradiation time, and $k$ is the first-order rate constant. The fitting of the experimental data was satisfactory for all the samples.

The half-life $\left(t_{1 / 2}\right)$ of MCPA and mecoprop, time required for its concentration to decrease to half its initial value, is related to the rate constant by the following equation: $t_{1 / 2}=$ $\ln 2 / k$.

Results are expressed as mean \pm standard error (3 independent samples). Statistically significant difference was determined using the Student's $t$-test and analysis of variance (Anova) with $P=0.05$ as a minimal level of significance.

\section{Results and Discussion}

3.1. Phase Solubility Studies. The stoichiometric ratio and stability constants of the inclusion complexes were derived from the changes in the solubility between MCPA and mecoprop in the presence of increasing amounts of HP- $\beta$ $\mathrm{CD}$, measured by UV spectrophotometry. Figure 1 presents the phase solubility plots obtained for MCPA and mecoprop and increasing concentrations of $\mathrm{HP}-\beta-\mathrm{CD}$ in water at $25^{\circ} \mathrm{C}$.

As can be seen, it shows AL type solubility diagrams as the MCPA and mecoprop solubility increases with increasing HP- $\beta$-CD concentrations, according to the classification established by Higuchi and Connors [25]. Table 1 summarizes the MCPA and mecoprop solubility, slopes, stability constants, and correlation coefficients of the phase solubility diagrams. Results evidenced that MCPA and mecoprop solubility is enhanced by the HP- $\beta$-CD inclusion complexation. Moreover, since the slope of the diagrams is less than 1 
TABLE 1: Complex formation parameters for MCPA/HP- $\beta$-CD and mecoprop/HP- $\beta$-CD systems in water at $25^{\circ} \mathrm{C}$.

\begin{tabular}{lcccc}
\hline Herbicide & $S_{0}(\mathrm{mM})$ & $\alpha$ & $K_{s}\left(\mathrm{M}^{-1}\right)$ & $R^{2}$ \\
\hline MCPA & $2.22 \pm 0.04$ & $0.45 \pm 0.03$ & $334 \pm 9$ & 0.9993 \\
Mecoprop & $3.12 \pm 0.03$ & $0.47 \pm 0.05$ & $282 \pm 5$ & 0.9990 \\
\hline
\end{tabular}

$S_{0}$ represents the solubility of MCPA or mecoprop; $\alpha$ : slope; $K_{s}$ : stability constant.

(Table 1), the complex stoichiometry was assumed to be $1: 1$ $[23,25]$.

The maximum concentration of MCPA and mecoprop in aqueous solution determined in absence of $\mathrm{HP}-\beta-\mathrm{CD}$ at $25^{\circ} \mathrm{C}$ was of $2.22 \mathrm{mM}$ and $3.12 \mathrm{mM}$, respectively. An increase in MCPA and mecoprop solubility was observed with increasing $\mathrm{HP}-\beta-\mathrm{CD}$ concentrations, and a solubility limit was determined at $35 \mathrm{mM} \mathrm{HP}-\beta-\mathrm{CD}$, which corresponds to the maximum solubility of HP- $\beta$-CD in water at $25^{\circ} \mathrm{C}$.

The results found show that, under the experimental conditions used, the $K_{s}$ values obtained for MCPA and mecoprop inclusion complexes are comparable. This data suggest that the interaction of HP- $\beta$-CD with MCPA and mecoprop should be quite similar, which can be ascribed to the similarity between both herbicides' molecular structures (Scheme 1). Moreover, the association constant for MCPA/HP- $\beta$-CD complex was $334 \mathrm{M}^{-1}$ which is more than twofold higher than that described for MCPA/ $\beta$-CD complex, indicating that the interaction of HP- $\beta$-CD with MCPA is stronger than that of $\beta-\mathrm{CD}[23]$.

3.2. Photodegradation Studies. Previous voltammetric experiments have been carried out for investigation of the electrochemical properties of MCPA and mecoprop in glassy carbon (GC) and GC-modified electrodes [24]. Both herbicides present a single oxidation wave, $E_{p}=+1.21 \mathrm{~V}$, corresponding to an oxidation process proceeding at the aromatic nucleus, through an electron transfer, via the formation of a cation radical intermediate that undergoes further reaction, namely, the cleavage of the ether linkage [24]. Based on the redox features of MCPA and mecoprop, a simple electroanalytical procedure has been developed for the monitoring of these herbicides in natural waters [24].

The degradation of MCPA and mecoprop was followed by SQW voltammetric measurements of the remaining concentrations of the herbicides or their HP- $\beta$-CD complexes in aqueous solution under simulated solar radiation. The concentrations of MCPA and mecoprop during photodegradation were monitored by observing the current intensity of the oxidation peak occurring at $E_{p}=+1.21 \mathrm{~V}$, as shown in Figure 2 (peak 1). The intensities of this peak decreased gradually during the degradation process reflecting the degradation of MCPA and mecoprop (Figure 2). Throughout the voltammetric monitoring of the degradation process occurring for MCPA and mecoprop in water, it was possible to observe the appearance of a second oxidation wave, $E_{p}=+0.76 \mathrm{~V}$ (peak 2, Figure 2). This second peak occurs as a result of the oxidation of the phenolic group existing in the molecular structure of the main intermediate, 4chloro-2-methylphenol, that is produced upon photolysis of MCPA and mecoprop (Scheme 1). In fact, it has been already reported that the major photodegradation pathway of MCPA and mecoprop involves elimination of the side chain, resulting in the formation of 4-chloro-2-methylphenol (Scheme 2) [17, 18, 26].

The percentages of free and HP- $\beta$-CD-complexed MCPA and mecoprop concentrations (obtained by SQW analyses) were plotted as a function of time, as shown in Figures 3 and 4.

The photodegradation kinetics of MCPA and mecoprop disappearance was of first order in all cases (ultrapure and river water). In fact, MCPA and mecoprop photodegradation profile followed an exponential decay showing that they are clearly affected by photoirradiation in solution. On the contrary, no disappearance of MCPA or mecoprop has been detected in the dark experiments (Figures 3 and 4), demonstrating that the disappearance of these herbicides was only due to photodegradation. The irradiation time for each aqueous media depended on the MCPA and mecoprop degradation rates and continued until total herbicides' loss, which took place after $c a .130 \mathrm{~h}$. The photodegradation rates of MCPA and mecoprop were lower in river water than in ultrapure water, showing that there is a dependency between the degradation of MCPA and mecoprop and the constitution of the irradiated media. This inhibiting effect of the components of river water may result from light attenuation induced by natural water constituents $[9,27]$. Table 2 lists the values of the rate constants $(k)$, half-lives $\left(t_{1 / 2}\right)$, and the linear regression coefficients for the kinetics of the photodegradation of MCPA and mecoprop for simulated solar irradiation. The results found for MCPA are in good agreement with the data described in literature $[8,27]$.

The irradiation of MCPA and mecoprop in aqueous solution in the presence of HP- $\beta$-CD ( $35 \mathrm{mM}$ ) showed a significant decrease in the degradation of herbicide throughout the course of irradiation, demonstrating the photoprotective effect of the cyclodextrin (Figures 3 and 4).

Actually, both MCPA and mecoprop were more slowly photodegraded in all the waters studied producing firstorder rate constants of 26.8 versus 8.6 and 34.4 versus 10.9 for ultrapure water and 23.0 versus 6.4 and 15.0 versus 8.7 for river water, respectively (Table 2 ). In general, the halflives were increased approximately by a factor of three. The microencapsulation in HP- $\beta$-CD seems to act as a physical barrier, through which the encapsulated MCPA and mecoprop are protected for some time against the action of light. This may explain why the residual concentrations of MCPA and mecoprop are much higher in the irradiated samples when herbicides are encapsulated in HP- $\beta$-CD than in the free form after $130 \mathrm{~h}$ (Figures 3 and 4).

The photodegradation of MCPA and its methylated homologous mecoprop (Scheme 1) appears to be influenced by the structural features of these herbicides. The half-lives of HP- $\beta$-CD encapsulated MCPA and mecoprop are 80.6 versus 63.6 for ultrapure water and 108.0 versus 79.7 for river water, respectively. Assuming that the photocatalytic transformation of MCPA and mecoprop into 4-chloro-2methylphenol can result, as suggested in the literature, from the oxidation of methylene group and/or from a substitution 


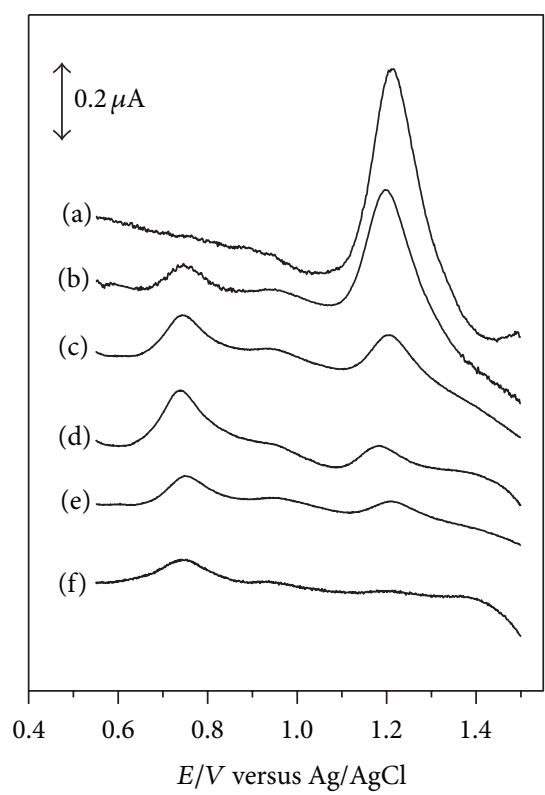

(A)

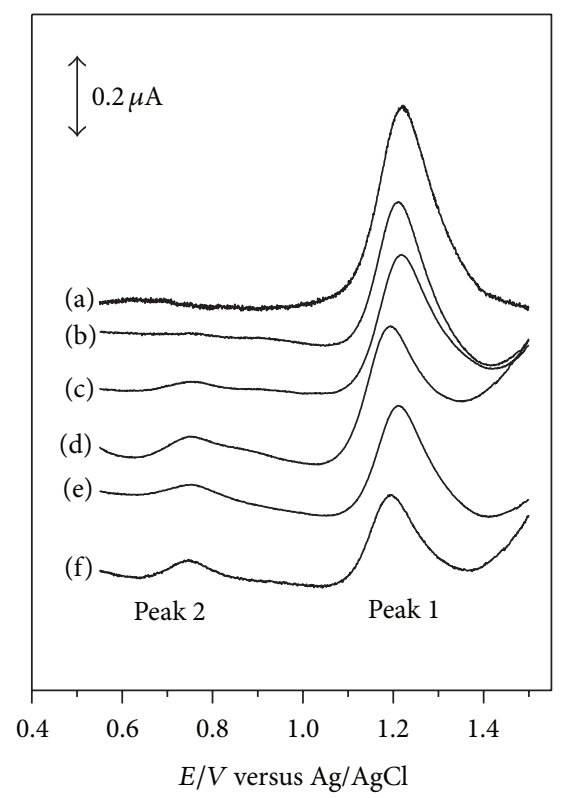

(B)

FIGURE 2: Square wave voltammograms obtained for the photodegradation of $0.5 \mathrm{mM}$ solutions of MCPA in the (A) absence and (B) presence of $35 \mathrm{mM}$ concentration of HP- $\beta$-CD after (a) 0 , (b) 25, (c) 50, (d) 65, (e) 75, and (f) 130 hours of irradiation in pH 4 acetate buffer electrolyte. Scan rate: $50 \mathrm{mV} \mathrm{s}^{-1}$.

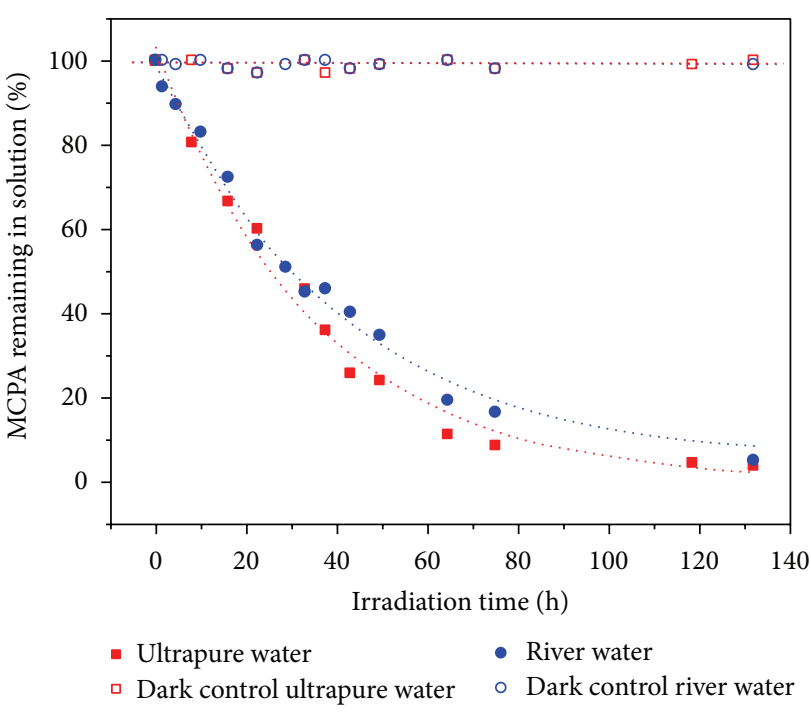

(a)

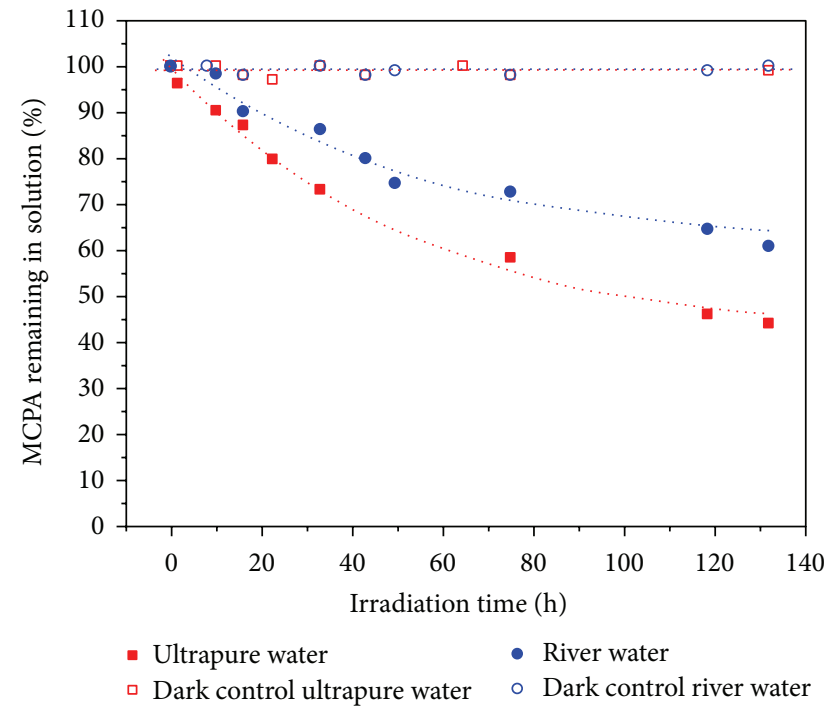

(b)

FIGURE 3: Photodegradation of (a) MCPA and (b) MCPA/HP- $\beta$-CD inclusion complexes in (open red square, solid red square) ultrapure and (open blue circle, solid blue circle) river water under simulated solar irradiation.

of the side chain by hydroxyl radicals, it is clear that the methyl group existing in mecoprop molecular structure has a positive influence on the stabilization of the radical intermediate (Scheme 2) [17, 18]. In either case, the formation of tertiary alkyl radical and/or the phenoxyl radical in the first stage of decomposition of mecoprop seems to be thermodynamically favoured relative to MCPA which may be explained considering the electron-donating ability of the methyl group.
The results found demonstrated the effectiveness of HP$\beta$-CD complexation in improving the photostability of MCPA and mecoprop, preventing and reducing the degradation processes occurring in aqueous solution.

\section{Conclusions}

Direct photodegradation appears to be an efficient system for the degradation of chlorophenoxy herbicides MCPA and 


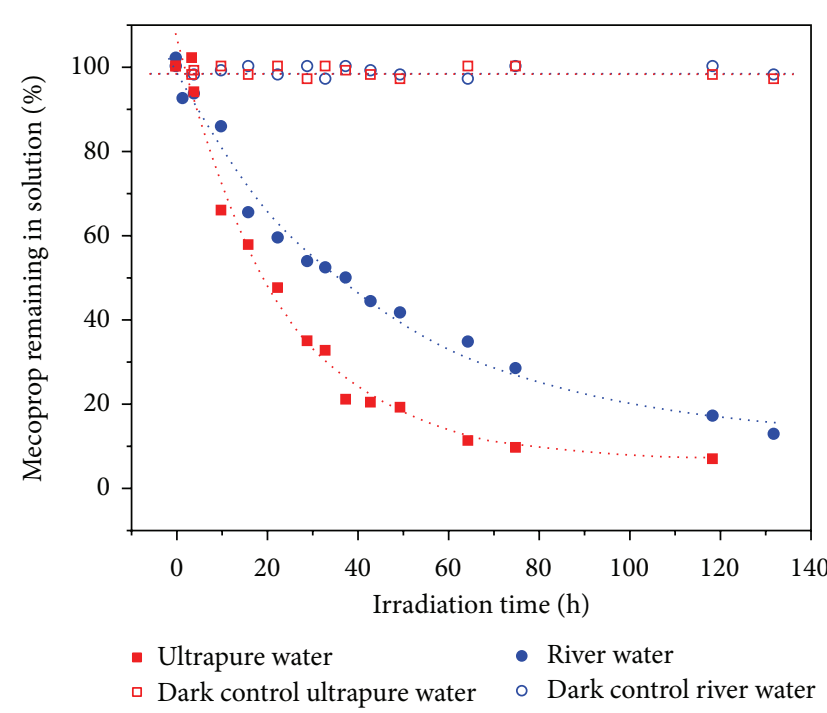

(a)

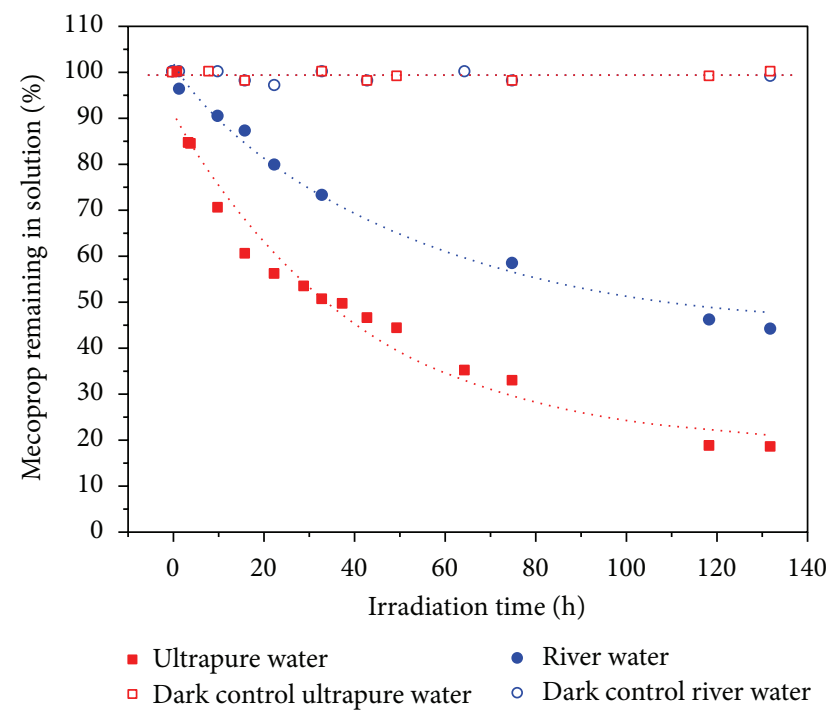

(b)

FIGURE 4: Photodegradation of (a) mecoprop and (b) mecoprop/HP- $\beta$-CD inclusion complexes in (open red square, solid red square) ultrapure and (open blue circle, solid blue circle) river water under simulated solar irradiation.

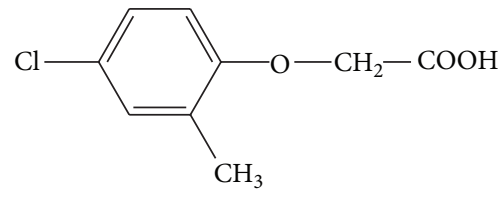

$$
\begin{aligned}
& +{ }^{\bullet} \mathrm{OH}\left(\mathrm{TiO}_{2}, h v\right) \\
& -\mathrm{H}_{2} \mathrm{O}
\end{aligned}
$$

(a)<smiles>CCCO</smiles>

(b)

$>\mathrm{OH}$<smiles>Cc1cc(Cl)cc(O)c1OCC(=O)O</smiles><smiles>Cc1cc(Cl)ccc1OCC(=O)O</smiles>

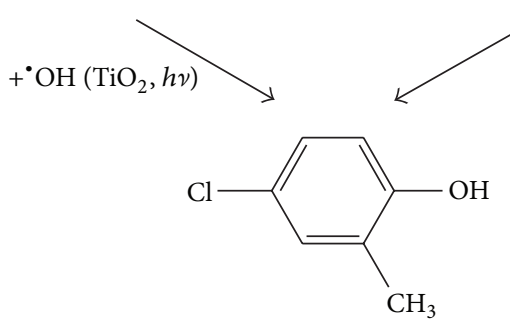

Scheme 2: Proposed pathways of MCPA photodegradation in the presence of $\mathrm{TiO}_{2}$ suspension: (a) oxidation of methylene group [17]; (b) substitution of the side chain [18]. 
TABLE 2: Kinetic parameters of MCPA and mecoprop photodegradation in different aqueous media.

\begin{tabular}{|c|c|c|c|c|c|}
\hline Herbicide & Concentration HP- $\beta$-CD (mM) & Water type & $k\left(10^{-3} \cdot \mathrm{h}^{-1}\right)$ & $t_{1 / 2}(\mathrm{~h})$ & $R^{2}$ \\
\hline \multirow{4}{*}{ MCPA } & \multirow{2}{*}{0} & Ultrapure & $26.8 \pm 0.4$ & $25.9 \pm 0.5$ & 0.97 \\
\hline & & River & $23.0 \pm 0.6$ & $30.1 \pm 0.6$ & 0.99 \\
\hline & \multirow{2}{*}{35} & Ultrapure & $8.6 \pm 0.3$ & $80.6 \pm 0.9$ & 0.99 \\
\hline & & River & $6.4 \pm 0.3$ & $108.0 \pm 1.2$ & 0.99 \\
\hline \multirow{4}{*}{ Mecoprop } & \multirow{2}{*}{0} & Ultrapure & $34.4 \pm 0.7$ & $20.2 \pm 0.8$ & 0.98 \\
\hline & & River & $15.0 \pm 0.5$ & $46.2 \pm 0.7$ & 0.99 \\
\hline & \multirow{2}{*}{35} & Ultrapure & $10.9 \pm 0.4$ & $63.6 \pm 0.6$ & 0.99 \\
\hline & & River & $8.7 \pm 0.4$ & $79.7 \pm 1.1$ & 0.98 \\
\hline
\end{tabular}

mecoprop. As microencapsulation has been shown to be a versatile tool for production of controlled release agricultural formulations, the inclusion complexes of MCPA and mecoprop with HP- $\beta$-CD have been prepared. The formation of MCPA/HP- $\beta$-CD and mecoprop/HP- $\beta$-CD inclusion complexes increased significantly the photostability of both herbicides in aqueous solutions. In general, the half-lives of the herbicides inclusion complexes were increased approximately by a factor of three related to the free molecules. It has been shown that the photodegradation of MCPA and mecoprop is influenced by their structural features. The additional methyl group existing in mecoprop molecular structure has a positive influence on the stabilization of the radical intermediate formed in the first stage of the photodegradation of both herbicides.

The gathered results suggest that the formation of inclusion complexes with cyclodextrins can improve the properties of formulations containing MCPA and mecoprop, minimizing the losses of these herbicides by photolysis and therefore increase the effectiveness of the herbicide in future applications.

\section{Conflict of Interests}

The authors of this work have no competing interests that could influence the results or discussion of this paper.

\section{Acknowledgments}

The financial support from Fundação para a Ciência e Tecnologia FCT/MCTES Project PTDC/AGRAAM/105044/ 2008, National Funds PIDDAC also cofinanced by the European Community Fund FEDER through COMPETE, Programa Operacional Factores de Competitividade (POFC), is gratefully acknowledged.

\section{References}

[1] T. Cserháti and E. Forgács, "Phenoxyacetic acids: separation and quantitative determination," Journal of Chromatography B, vol. 717, pp. 157-178, 1998.

[2] A. Jankowska, M. Biesaga, P. Drzewicz, M. Trojanowicz, and K. Pyrzyńska, "Chromatographic separation of chlorophenoxy acid herbicides and their radiolytic degradation products in water samples," Water Research, vol. 38, no. 14-15, pp. 32593264, 2004.

[3] G. Sandhya and S. S. S. Kushwaha, "Photo-oxidative degradation and quantification of herbicide residues for pesticidal pollution," Research Journal of Chemistry and Environment, vol. 12, no. 4, pp. 89-95, 2008.

[4] P. A. Scherr, G. B. Hutchison, and R. S. Neiman, "Non-Hodgkin's lymphoma and occupational exposure," Cancer Research, vol. 52, no. 19 , supplement, pp. 5503s-5509s, 1992.

[5] L. Miligi, A. S. Costantini, A. Veraldi et al., "Cancer and pesticides: an overview and some results of the Italian multicenter case-control study on hematolymphopoietic malignancies," Annals of the New York Academy of Sciences, vol. 1076, pp. 366377, 2006.

[6] M. Kogevinas, H. Becher, T. Benn et al., "Cancer mortality in workers exposed to phenoxy herbicides, chlorophenols, and dioxins: an expanded and updated International Cohort Study," American Journal of Epidemiology, vol. 145, no. 12, pp. 1061-1075, 1997.

[7] Eurostat, The Use of Plant Protection Products in the European Union: Data 1992-2003, Office for official publications of the European Communities, Luxembourg, Belgium, 2007.

[8] S. J. Stangroom, C. L. MacLeod, and J. N. Lester, "Photosensitized transformation of the herbicide 4-chloro-2-methylphenoxy acetic acid (MCPA) in water," Water Research, vol. 32, no. 3, pp. 623-632, 1998.

[9] D. Vione, S. Khanra, R. Das et al., "Effect of dissolved organic compounds on the photodegradation of the herbicide MCPA in aqueous solution," Water Research, vol. 44, no. 20, pp. 6053$6062,2010$.

[10] A. Yuzir, S. Chelliapan, and P. J. Sallis, "Impact of the herbicide (RS)-MCPP on an anaerobic membrane bioreactor performance under different COD/nitrate ratios," Bioresource Technology, vol. 109, pp. 31-37, 2012.

[11] A. A. Piwowarczylk and N. M. Holden, "Phenoxyalkanoic acid herbicide sorption and the effect of co-application in a Haplic Cambisol with contrasting management," Chemosphere, vol. 90, pp. 535-541, 2013.

[12] X. Ren, Y. Sun, Z. Wu, F. Meng, and Z. Cui, "The OH-induced degradation mechanism of 4-chloro-2-methylphenoxyacetic acid (MCPA) with two forms in the water: a DFT comparison," Chemosphere, vol. 88, no. 1, pp. 39-48, 2012.

[13] H. D. Burrows, M. Canle L, J. A. Santaballa, and S. Steenken, "Reaction pathways and mechanisms of photodegradation of pesticides," Journal of Photochemistry and Photobiology B, vol. 67, no. 2, pp. 71-108, 2002. 
[14] F. Sopeña, C. Maqueda, and E. Morillo, "Controlled release formulations of herbicides based on micro-encapsulation," Ciencia e Investigación Agraria, vol. 35, pp. 27-42, 2009.

[15] H. B. Scher, Ed., Controlled-Release Delivery Systems for Pesticides, Marcel Dekker, New York, NY, USA, 1999.

[16] A. Markus, "Advances in the technology of controlled-release pesticide formulations," in Microencapsulation: Methods and Industrial Applications, S. Benita, Ed., pp. 73-91, Marcel Dekker, New York, NY, USA, 1996.

[17] A. Topalov, B. Abramović, D. Molnár-Gábor, J. Csanádi, and O. Arcson, "Photocatalytic oxidation of the herbicide (4-chloro2-methylphenoxy)acetic acid (MCPA) over $\mathrm{TiO}_{2}$," Journal of Photochemistry and Photobiology A, vol. 140, no. 3, pp. 249-253, 2001.

[18] A. Zertal, T. Sehili, and P. Boule, "Photochemical behaviour of 4-chloro-2-methylphenoxyacetic acid: influence of $\mathrm{pH}$ and irradiation wavelength," Journal of Photochemistry and Photobiology A, vol. 146, no. 1-2, pp. 37-48, 2001.

[19] J. Szejtli, "Past, present, and future of cyclodextrin research," Pure and Applied Chemistry, vol. 76, no. 10, pp. 1825-1845, 2004.

[20] H. Dodziuk, Cyclodextrins and Their Complexes: Chemistry, Analytical Methods, Applications, John Wiley \& Sons, 2006.

[21] J. I. Pérez-Martínez, E. Morillo, and J. M. Ginés, “ $\beta$-CD effect on 2, 4-D soil adsorption," Chemosphere, vol. 39, pp. 2047-2056, 1999.

[22] N. M. Rougier, D. L. Cruickshank, R. V. Vico et al., "Effect of cyclodextrins on the reactivity of fenitrothion," Carbohydrate Research, vol. 346, no. 2, pp. 322-327, 2011.

[23] E. M. Garrido, M. Santos, P. Silva, F. Cagide, J. Garrido, and F. Borges, "Host-guest complexes of phenoxy alkyl acid herbicides and cyclodextrins. MCPA and $\beta$-cyclodextrins," Journal of Environmental Science and Health B, vol. 47, pp. 869-875, 2012.

[24] V. Rahemi, J. J. Vandamme, J. M. P. J. Garrido, F. Borges, C. M. A. Brett, and E. M. P. J. Garrido, "Enhanced host-guest electrochemical recognition of herbicide MCPA using a $\beta$-cyclodextrin carbon nanotube sensor," Talanta, vol. 99, pp. 288-293, 2012.

[25] T. Higuchi and K. A. Connors, "Phase-solubility techniques," Advances in Analytical Chemistry and Instrumentation, vol. 4, pp. 117-212, 1965.

[26] L. Meunier and P. Boule, "Direct and induced phototransformation of mecoprop [2-(4-chloro-2-methylphenoxy)propionic acid] in aqueous solution," Pest Management Science, vol. 56, no. 12, pp. 1077-1085, 2000.

[27] S. Chiron, C. Minero, and D. Vione, "Photodegradation of xenobiotic compounds relevant to estuarine waters," Annali di Chimica, vol. 97, no. 3-4, pp. 135-139, 2007. 

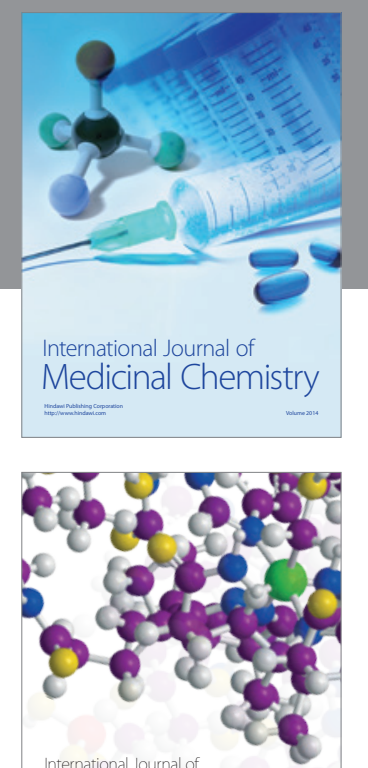

\section{Carbohydrate} Chemistry

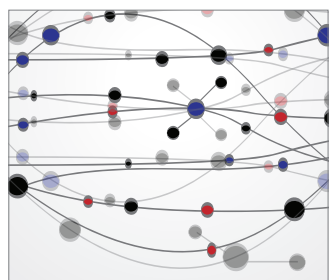

The Scientific World Journal
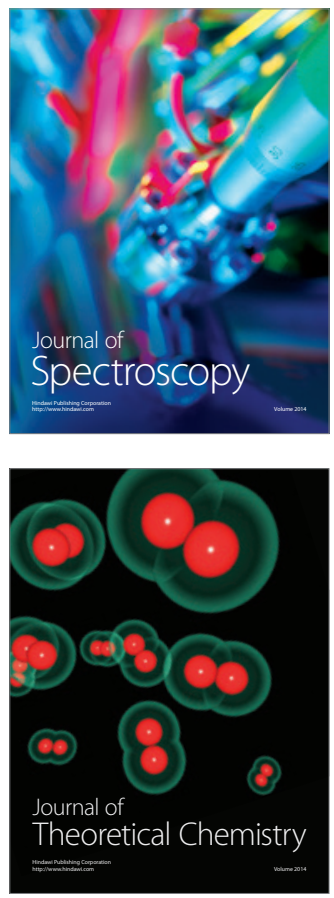
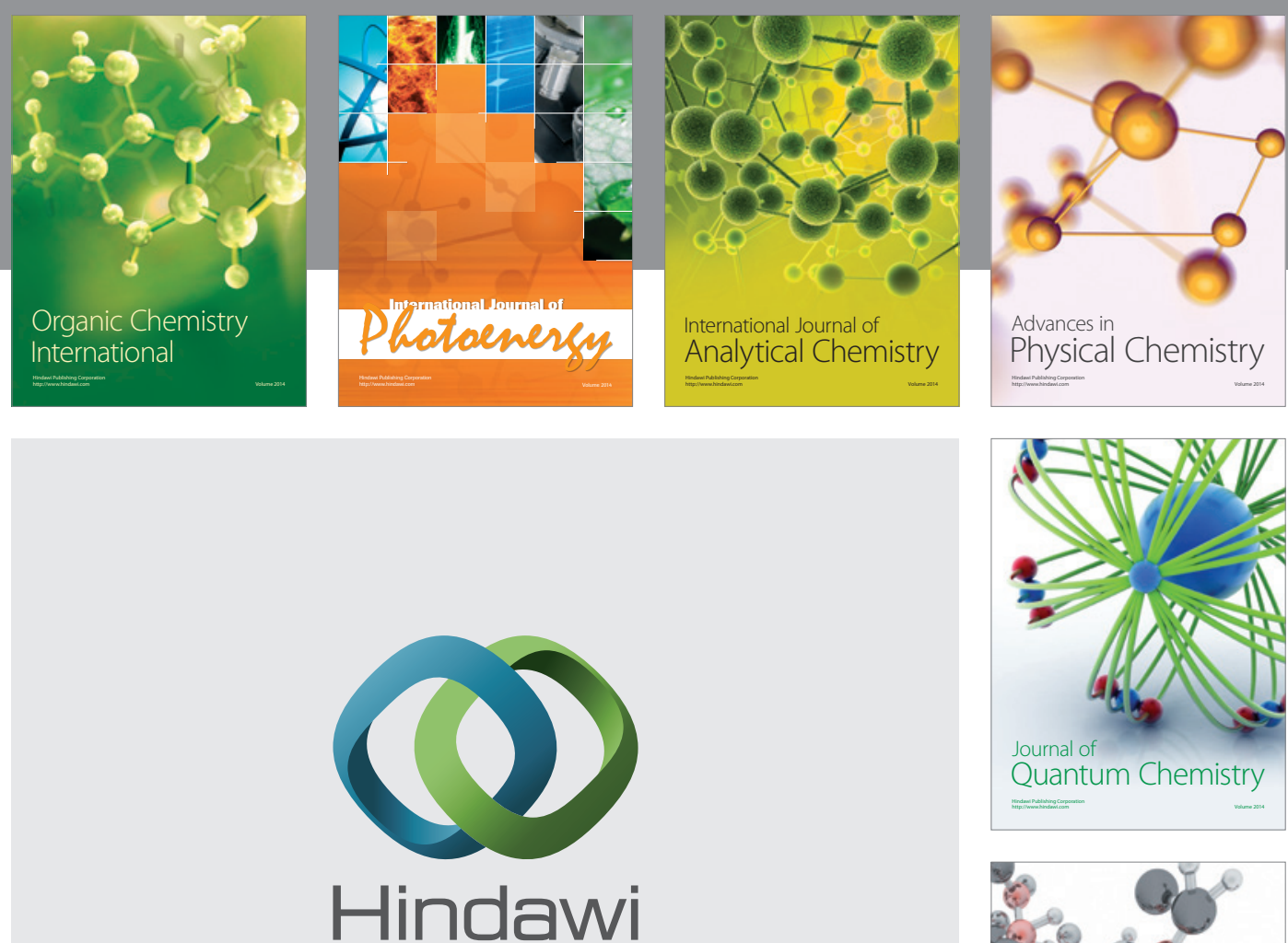

Submit your manuscripts at

http://www.hindawi.com

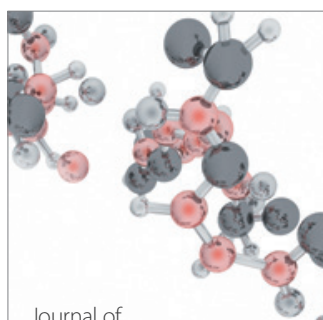

Analytical Methods

in Chemistry

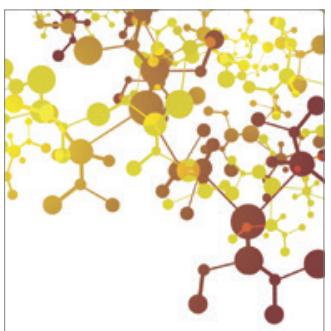

Journal of

Applied Chemistry

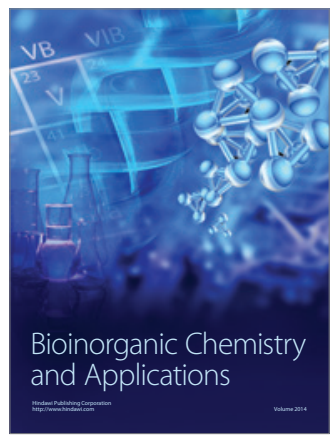

Inorganic Chemistry
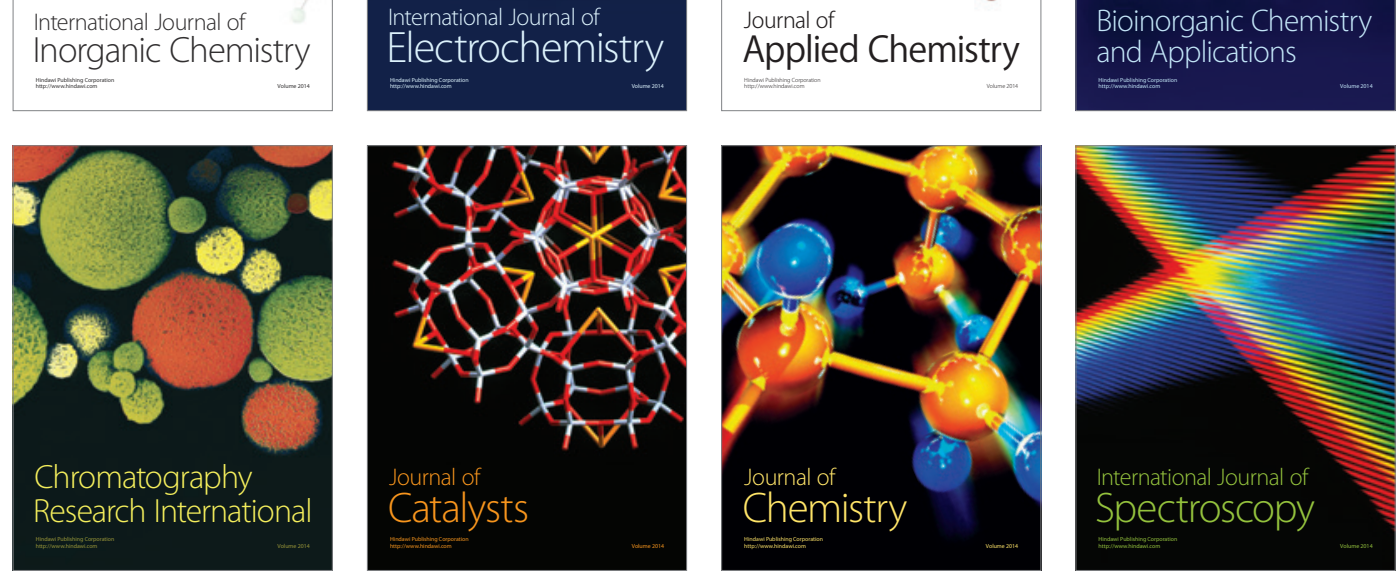